\title{
LITERATURA INFANTIL NAS SÉRIES INICIAIS DO ENSINO \\ FUNDAMENTAL I: SABERES E METODOLOGIAS
}

\section{Children's literature in the early grades of elementary school: knowledge and methodologies}

\author{
Maurício SILVA,UNINOVE ${ }^{1}$ \\ Wendel CHRISTAL,UNINOVE ${ }^{2}$
}

\begin{abstract}
RESUMO: Este artigo procura analisar alguns aspectos básicos da Literatura Infantil, como suas particularidades estéticas, suas funções práticas e, sobretudo, sua relação com a educação. $O$ presente artigo propõe ainda algumas metodologias para se trabalhar a literatura infantil na sala de aula das séries iniciais.
\end{abstract}

PALAVRAS-CHAVE: Literatura infantil; Educação; Metodologia;Séries Iniciais.

ABSTRACT: This paper analyzes some basic aspects of Children's Literature, detaching its aesthetic peculiarities, its practical functions, and especially its relation with education. This paper also proposes a methodology to work with Children's Literature in lower-grade classrooms.

KEY WORDS: Children's Literature; Education; Methodology;Early Grades.

\section{Introdução}

Como em nenhuma outra manifestação artístico-cultural, a Literatura Infantil possui a prerrogativa de tornar os fatos que compõem a natureza estética do fenômeno artístico inapelavelmente presentes, na medida em que privilegia o discurso imaginário e trabalha a partir de temas e motivos particularmente simbólicos. Sem ter nascido como um produto criado a priori para o deleite da criança, a Literatura Infantil surge, antes, como resultado de um vasto complexo cultural, que abrange desde as manifestações populares tradicionais até os meios de comunicação recentes, com os quais estabelece um diálogo cada vez mais intenso.

Essa literatura inaugural, a que podemos chamar de tradicional, é sobretudo marcada pela oralidade, registrada na memória coletiva dos povos, geralmente anônima e de extração folclórica. Nela encontra-se, a rigor, a gênese da Literatura Infantil, razão de sua vitalidade como manifestação cultural e inesgotável fonte de inspiração da

\footnotetext{
${ }^{1}$ Doutor em Letras Clássicas e Vernáculas pela Universidade de São Paulo.maurisil@gmail.com

${ }^{2}$ Doutorando em Educação na Universidade Nove de Julho.wendelchristal@ yahoo.com.br
} 
histórias destinadas às crianças:

em todas as latitudes, e desde sempre, é a Literatura Tradicional a primeira a instalar-se na memória da criança. Ela representa o seu primeiro livro, antes mesmo da alfabetização, e o único, nos grupos sociais carecidos de letras. [As histórias pertencentes à tradição oral dos povos são] a contribuição mais profunda na Literatura Infantil (MEIRELES, 1979, p. 66/69).

Contudo, na medida em que estamos falando de uma manifestação essencialmente artística, cujos fundamentos ontológicos estão mais relacionados a sua natureza estética do que a eventuais desdobramentos pedagógico-formativos, deve-se atentar para o fato de que a literatura infantil adquire seu valor enquanto discurso literário exatamente ao privilegiar aspectos relacionados ao universo da criação, em detrimento daqueles relacionados ao universo da formação, estes últimos muito mais apropriados ao âmbito das práticas educacionais.

É por isso que, pode-se dizer, a Literatura Infantil privilegia a intenção artística na relação autor/leitor e valoriza o enfoque fantasista na releitura que promove da realidade circundante, o que resulta, no final das contas, num constante estímulo à criatividade infantil, isto é, à sua imaginação criadora:

a Literatura Infantil ocupa no acervo das bibliotecas um lugar privilegiado, constituindo-se num elemento desencadeador de atividades criativas (...) A história não acaba quando chega ao fim. Ela permanece na mente da criança, que a incorpora como um alimento de sua imaginação criadora (COELHO, 1999, 35/59).

Não se pode prescindir, quando se trata desse assunto, de uma das questões mais importantes à boa interação entre a Literatura Infantil e a criança: a adequação entre a faixa etária do leitor e o livro que lhe é oferecido e que lhe servirá de passaporte na aventura de descoberta do universo imaginativo contido na narrativa ficcional. Muitas vezes, a falta de atenção para esse fato tão simples é a responsável pelo desinteresse que a criança manifestará, quando adulta, pela leitura, num processo de distanciamento e aversão ao livro que se pode tornar irreversível.

A responsabilidade do educador faz-se também, neste sentido, nos interstícios a atividade formadora, no momento de dirigir os interesses da criança para uma leitura que não apenas lhe será agradável naquele momento, mas que desencadeará todo um processo de amadurecimento do interesse para leituras futuras, para um contato atemporal com a literatura.

Esta é, em poucas palavras, a opinião balizada de Nelly Novaes Coelho, ao 
expor o problema nos seguintes termos:

torna-se urgente que os responsáveis pelas leituras da criançada atentem para a adequação entre o livro e a possível fase psicológica (ou faixa etária) em que ela se encontra (...) Se atendermos às exigências de cada fase, a criança passará, sem problemas, do interesse espontâneo pela linguagem visual imagética, para o interesse mais profundo pela linguagem verbal escrita. $\mathrm{O}$ não respeitarmos a evolução natural de seu psiquismo (forçando-a a leituras ou atividades intelectuais inadequadas), poderá impedi-la, para sempre, do importante encontro com o mundo da palavra nos livros (COELHO, 1984, p. 144).

Pautando-se, portanto, nas teorias propostas pela Psicologia do Desenvolvimento, tais como aquelas formuladas por Piaget, podemos dividir os períodos de desenvolvimento da criança e do adolescente em cinco tipos diferentes, correspondentes a grupos etários distintos e cronologicamente dispostos, a fim de melhor visualizar o processo de adequação dos leitores à produção ficcional infantil.

Um primeiro tipo, aquele que podemos genericamente chamar de Primeira Infância, correspondente às crianças de um ano e meio a três anos, prevê aperfeiçoamentos diversos por parte da criança, como a sensibilidade tátil, o desenvolvimento da maturidade, a exploração dos sentidos, a descoberta de formas concreta, a conquista da linguagem etc. Para esta faixa etária, aconselha-se a utilização de livros com imagens, com texturas diferentes, livros-brinquedo, livros musicais e afins, em geral contendo narrativas curtas, com muitas imagens, de enredo simples e vivo, com poucas personagens e que se aproximem da vivência da criança.

Um segundo tipo, o da Segunda Infância, de crianças de três a seis anos, assinala o desenvolvimento da fantasia e da imaginação infantis, o predomínio do pensamento mágico, o aumento do vocabulário, a não-diferenciação entre a fantasia e a realidade, o interesse pelo maravilhoso etc. Para essa fase é recomendável os livros com imagens que já apresentem correspondência com as palavras, contendo, sobretudo, narrativas curtas com a presença do humor, certo clima de expectativa ou mistério e toda sorte de discursos ligados à imaginação (fábulas, contos de fadas, lendas etc.).

É no terceiro tipo, o da Terceira Infância, dos sete aos onze anos, que a criança começa a desenvolver, com mais intensidade, o pensamento racional e o processo de socialização, resultando na substituição do pensamento mágico pelo lógico, embora o interesse pelo maravilhoso ainda persista. Os livros adequados para essa faixa etária são aqueles que apresentem aventuras e ação constantes, além de livros de mistério e narrativas exemplares. Logicamente, com o processo de alfabetização em franca evolução, a criança - entrando agora na puberdade - passa a se interessar por narrativas 
escritas, de extensão mediana, com o predomínio do concreto sobre o abstrato.

A literatura que se produz para esses três primeiros grupos, representando a infância e suas subdivisões, apresenta características muito singulares, na medida em que há, nessa fase do desenvolvimento humano, não apenas uma necessidade intrínseca do lúdico, mas também uma curiosidade muito intensa, que se liga de imediato à inteligência. A literatura, neste sentido, desempenha um papel relevante, procurando prover as necessidades mais íntimas das crianças, ainda que nem sempre elas sejam muito claras para as próprias crianças. Como já se afirmou uma vez, "o bom livro para crianças é (...) aquele que pretende consultar as suas características psíquicas e responder a suas exigências intelectuais e espirituais” (AMARAL, 1971, p. 13).

No quarto tipo, o da Pré-Adolescência, numa faixa etária que vai dos onze aos dezesseis anos, revela-se maior grau de pensamento reflexivo, resultando em maior autoconfiança e aprofundamento do abstrato (sobretudo em relação ao tempo e ao espaço). O interesse volta-se, quase que naturalmente, para os livros que contenham textos mais longos, com histórias de heróis, temas emotivos e sentimentais, motivos cotidianos e uma diversidade de assuntos, própria da curiosidade do pré-adolescente e do adolescente.

Finalmente, o quinto e último tipo, correspondente à Adolescência, a partir dos dezessete anos, manifesta maior espírito aventuresco, muitas vezes buscando explicação para a essência e fenômenos da realidade, correspondendo, via de regra, ao desenvolvimento da maturidade física e psíquica. Uma variedade enorme de tipos de livros é colocada à disposição dessa faixa etária, destacando-se os que contêm narrativas de aventuras e ficção científica, histórias humorísticas e até narrativas existencialistas.

O quadro aqui esboçado, embora simples, revela-nos a responsabilidade do educador no papel de mediador entre a criança/adolescente e a literatura, uma vez que prescreve, para cada faixa etária, no processo de desenvolvimento humano, um tipo relativamente específico de livro e de narrativa. Dessa maneira, qualquer que seja a faixa etária de que se esteja tratando, a provisão adequada da Literatura Infantil resulta numa inegável contribuição para o desenvolvimento da inteligência e da sensibilidade humanas e, consequentemente, para o processo de interação social:

no aspecto físico, um ambiente rico em estimulação irá proporcionar objetos que possam ser manipulados pela criança, lugares que possam ser explorados, oportunidades de observação de fenômenos da natureza etc. No plano social, o ambiente será rico em estimulação quando reforçar e valorizar a aquisição de competência da criança em muitos e muitos aspectos (RAPPAPORT, 1981, p. 56). 


\section{Saberes para o Ensino da Literatura infantil}

Pode-se dizer que a Literatura Infantil é o resultado da interação entre intenção pedagógica do texto ficcional - a qual estimula o aprendizado - e sua intenção lúdica que, por sua vez, estimula a criatividade de uma forma geral, tudo, evidentemente, mediado pela natureza estética da literatura, que, no limite, fundamenta a própria concepção do que seja a arte: a estética acaba sendo, neste sentido, o princípio e fim de toda atividade artística.

Apesar disso - ou, sobretudo quando se trata da Literatura Infantil, por isso mesmo -, outros aspectos relacionados a essa manifestação artística agregam valores diversos à Literatura Infantil, tornando-a ainda mais adequada à criança e ao jovem e desempenhando imponderável papel no seu processo de formação.

Para efeito didático, podemos dividir em três os aspectos nos quais essa literatura incide, contribuindo para a formação/desenvolvimento da criança e do adolescente e permitindo, providencialmente, uma franca interação entre o lúdico e o pedagógico.

O primeiro aspecto que ressaltamos é o psicofísico, no sentido de que a Literatura Infantil atua como estímulo às funções motoras e intelectuais das crianças, além contribuir com a formação de sua personalidade, com o desenvolvimento do imaginário infantil e de seu espírito crítico. O segundo aspecto sobre o qual a Literatura Infantil age é de natureza social, já que, por meio dela, a criança adquire melhores condições de formar sua identidade social, aperfeiçoar seu processo de sociabilidade e estabelecer categorias de valor ligadas à ética. O terceiro aspecto, a que podemos chamar de lingüístico, liga-se à capacidade, promovida pela Literatura Infantil, de contribuir para o desenvolvimento do vocabulário, para a aquisição de estruturas linguísticas, para a distinção de registros discursivos e desenvolvimento da escrita e da narratividade.

Contudo, a discussão maior se trava não em torno desses aspectos que assinalamos, intrinsecamente relacionados à atuação da Literatura Infantil na formação da criança e do adolescente, mas em torno da possível dicotomia entre um valor lúdico (a-funcional) e um valor pedagógico (funcional) dessa literatura.

Com efeito, não são poucos, a exemplo de Maria Antonieta Cunha, que se colocam a favor da natureza estritamente lúdica da Literatura Infantil, assinalando não ser necessário seu pretenso tributo à Pedagogia, já que 
muitas obras feitas para crianças e ditas de literatura infantil não se desprendem de uma peculiaridade do discurso pedagógico: a redução da criança, notadamente pela facilitação artística (puerilidade) e pelo tom moralizador. Nesses casos, temos apenas uma pretensa literatura infantil, exatamente como, dentro da produção artística para adultos, existem também lamentáveis equívocos: há maus romances, maus poemas, maus contos (CUNHA, 1999, p. 26).

Há também, evidentemente, aqueles que, como Cecília Meireles, colocam-se com argumentos igualmente convincentes - a favor de uma pretensa natureza pedagógica da Literatura Infantil, rejeitando, até pela omissão de qualquer comentário favorável a este - seu possível caráter lúdico:

a Literatura não é, como tantos supõem, uma passatempo. É uma nutrição. A Crítica, se existisse, e em relação aos livros infantis, deveria discriminar as qualidades de formação humana que apresentam os livros em condições de serem manuseados pelas crianças (MEIRELES, 1979, p. 28).

Uma posição mais imparcial, acreditamos, é exatamente aquela que se pauta numa concepção intermediária do valor da Literatura Infantil, seja por considerar sua atuação a partir de uma perspectiva equilibrada, como ocorre em Nelly Novaes Coelho:

como 'objeto' que provoca emoções, dá prazer ou diverte e, acima de tudo, 'modifica' a consciência-de-mundo de seu leitor, a Literatura Infantil é Arte. Por outro lado, como 'instrumento' manipulado por uma intenção 'educativa, ela se inscreve na área da Pedagogia (COELHO, 1984, p. 25)

Ou por entender que a Literatura Infantil coloca-se como uma proto-pedagogia que atua, em conjunto com seu caráter lúdico, na formação da criança, como sugerem Maria José Palo e Maria Rosa Oliveira:

o verdadeiro sentido de uma ação pedagógica que é mais do que ensinar o pouco que se sabe, estar de prontidão para aprender a vastidão daquilo que não se sabe. A arte literária é um dos caminhos para esse aprendizado (...) À função utilitário-pedagógica só resta um caminho, que a leve ao verdadeiro diálogo com o ser literário infantil: propor-se enquanto proto-pedagogia ou quase-pedagogia, primeira e nascente, capaz de rever-se em sua estratificação de código dominador do ser literário infantil, para, ao recebê-lo em seu corpo, banhar-se também na qualidade sensível desse ser com o qual deve estar em harmônica convivência (PALO, 1992, p. 14).

Com efeito, é na interação entre os valores lúdico e pedagógico que se encontra a melhor definição do que seja a Literatura Infantil e o melhor entendimento de sua atuação sobre os aspectos psicofísico, social, linguísticos e outros, próprios do processo 
de desenvolvimento da criança e do adolescente.

\section{Metodologias para o Ensino da Literatura infantil}

Para que o mediador de leitura literária - como são, no final das contas, os professores - realize seu trabalho com êxito não é necessário muito recurso material, uma vez que o principal objeto utilizado por ele é o próprio livro e seus congêneres; em poucas palavras, seu papel é fazer com que a criança se aproxime do livro e se interesse por ele, tornando-se um leitor de fato. Assim, livre do caráter "obrigatório" da leitura, a criança é estimulada a buscar o livro por conta própria, inserindo-se naturalmente do universo da leitura.

Daí a necessidade de se aperfeiçoar, cada vez mais, as estratégias de atuação e os resultados da mediação de leitura, bem como de outras práticas voltadas para o desenvolvimento do gosto pela leitura dos textos literários. E a sala de aula, num sentido abrangente, é o espaço por excelência onde se começa a exercitar essa prática:

é só quando o aluno percebe que existe um ambiente de liberdade e respeito naquele local de trabalho [na sala de aula] que ele pode perceber o texto literário como um produto cultural com o qual interage de forma significativa. A formação de um ambiente de trabalho que possibilite a intervenção dos alunos na aula e no próprio texto literário é responsabilidade do professor (NORONHA, s.d., p. 19).

Desse modo, obtém-se, de forma mais eficaz, como resultado imediato dessa política, maior intimidade com o texto literário, primeiro passo para que se possa desenvolver no leitor em formação o tão debatido gosto pela leitura; por extensão, alcança-se também, como resultado desse processo, habilidade na manipulação de um instrumental adequado à análise e à interpretação da obra literária, desenvolvendo no leitor uma competência crítica.

Nesse sentido, seguem abaixo algumas sugestões práticas de como atuar na sala de aula, ambas inter-relacionadas - em especial como as séries iniciais do Ensino Fundamental I -, a fim de instrumentalizar o professor em sua atuação como mediador da literatura infantil. Apresentamos duas propostas metodológicas, cada uma delas subdividias em várias etapas. 


\section{Proposta metodológica 1}

Domínio: A descrição de um ser imaginário

Saberes Abordados: amizade, produção de texto, imaginário, gêneros textuais Público-alvo: Ensino Fundamental I

\subsection{Primeira etapa: diagnóstico do conceito de amizade trazido pela criança}

O professor perguntará para cada aluno o nome de um personagem que, na opinião deles, é exemplo de uma "boa amizade" em livros, filmes, desenhos, jogos, quadrinhos, etc. Os nomes deverão ser escritos em uma folha e entregues ao professor. Caso queira, o professor escolherá alguns nomes e perguntará ao aluno o porquê da escolha de tal personagem.

\subsection{Segunda etapa: narrar a história à sala}

O professor poderá ler o conto $O$ amigo de Juliana, de Eva Furnari³ ${ }^{3}$ ou fazer uma contação da história à sua maneira. Sugere-se dispor a sala em círculo.

\subsection{Terceira etapa: discussão da história}

Nesta etapa, o professor mediará uma pequena discussão com a sala sobre o entendimento da história. O professor poderá escolher alguns destes questionamentos que poderão auxiliá-lo: a) É uma história sobre quem? b) O que acontece com os personagens? c) Quem conta a história? d) Como são descritos Juliana e Fungo exteriormente? e) internamente, com o que cada um se preocupava mais? f) Por que a amizade dos dois andava estremecida? g) Ao reescrever a redação de Juliana, qual foi a intenção de Fungo? h) A família de Juliana a ajudava? Por quê? i) Qual redação ficou mais criativa e interessante? Por quê? j) O que é preciso para escrever bem e ter estilo, como Fungo?

\subsection{Quarta etapa: A imagem de um ser imaginário}

O professor apresenta à sala a ilustração de Fungo, que há no conto, e depois oferece aos alunos outros seres imaginários ilustrados ou não. Pode-se usar o data-show ou fazer um levantamento na lousa de alguns seres imaginários. A ênfase recairá apenas na descrição de um personagem imaginário.

\subsection{Quinta etapa: A criação textual de um ser imaginário}

\footnotetext{
${ }^{3} \mathrm{O}$ conto está disponível na íntegra em http://revistaescola.abril.com.br/lingua-portuguesa/pratica-
} 
O professor solicitará que, em grupos de mais ou menos quatro alunos, cada grupo crie um ser imaginário, inventando: nome, descrição física e psicológica (missão, valores, desejos etc.) do personagem. Feito isso, o professor recolherá as redações, corrigirá os textos e os entregará na próxima aula, solicitando que cada grupo corrija os problemas de linguagem apontados e reescreva a redação, que será novamente recolhida e reavaliada pelo professor. Ao final, pedir que cada aluno traga um objeto reciclável para a próxima aula.

\subsection{Sexta etapa: do texto à materialidade}

Em outra aula, as redações serão entregues aos alunos para que, novamente em grupos, eles transformem o ser imaginário, criado por eles na redação, em um personagem construído a partir do material trazido. O professor pode colaborar com o material, utilizando o que a escola pode fornecer para a elaboração dos seres imaginários.

\subsection{Sétima etapa: apresentação dos trabalhos}

Por fim, sugere-se apresentar os trabalhos à sala ou à escola: uma exposição dos seres imaginários, em algum espaço da sala ou da escola, com a redação fixada ao lado do ser imaginário.

\section{Proposta metodológica 2}

Domínio: Seres imaginários amigos

Saberes Abordados: amizade, produção de texto, imaginário, gêneros textuais Público-alvo: Ensino Fundamental I

\subsection{Primeira etapa: Retomada da Proposta Metodológica 1}

A proposta é pela continuidade do trabalho, mas o enfoque recairá sobre outro gênero textual: a narração. Inicialmente, sugere-se a retomada da história "O amigo de Juliana", de Eva Furnari, a partir da qual o professor dará ênfase aos principais elementos de um texto narrativo: narrador, personagem, tempo, espaço e enredo.

\subsection{Segunda etapa: o encontro de seres imaginários}

O professor novamente dividirá a sala em grupos e solicitará que dois grupos se juntem para criar um pequeno texto narrativo em que um personagem fará amizade com o outro, isto é, um entrará no "mundo" do outro. O objetivo é mostrar, em linhas gerais, 
que amizade requer participação na história do outro, como a história de Eva Furnari, por exemplo. Além disso, respeitando o nível escolar da sala, Ensino Fundamental 1, dever-se-á atentar para o tamanho do texto, que, por motivos práticos, não deverá ultrapassar cerca de 15-20 linhas.

\subsection{Terceira etapa: reescrevendo o texto}

Logo que as histórias forem elaboradas, o professor recolherá os textos, corrigirá todos eles e na aula seguinte e os distribuirá para que os alunos façam a correção. Esta pode ser feita individualmente, na lousa ou no data-show, com a ajuda de toda a sala.

\subsection{Quarta etapa: leitura das histórias e discussão acerca da amizade}

Sugere-se que as histórias sejam lidas e discutidas em sala. Neste momento, é importante que o professor observe, por exemplo, os valores expressos, explícita ou implicitamente, por meio dos textos, discutindo-os com os alunos.

\subsection{Quinta etapa: a confecção de um livro}

Assim que as histórias forem corrigidas, quantas vezes se fizerem necessárias, o professor poderá organizar e confeccionar um livro com as narrativas, o qual poderá ser elaborado na própria sala de aula, algo que demandará tempo e, possivelmente, um outro projeto; ou, ainda, este trabalho poderá ser feito com a colaboração da escola e dos pais, recorrendo-se, por exemplo, a uma editora ou fazendo uma edição independente

\subsection{Sexta etapa: apresentação dos trabalhos}

Finalmente, promover um dia de lançamento na escola com a participação dos pais, caso se opte por sua edição. Se não, é crucial a apresentação dos trabalhos à sala toda, ou, se possível, à escola, expondo os trabalhos, por exemplo. Ao final do processo, além do trabalho em nível temático sobre a amizade, os alunos terão lidado com a leitura, a produção textual, a reescrita de texto, a prática dos gêneros descrito e narrativo, enfim, todo um processo que aciona, com prazer e por meio do lúdico, a imaginação e a criatividade dos alunos, de modo a formar leitores e produtores de texto competentes, criativos e críticos. 


\section{Conclusão}

Nada do que aqui ficou dito prescinde dos pressupostos estéticos, por assim dizer, que fundamentam a própria natureza da Literatura Infantil. Não há, em última instância, literatura sem aquele "sentido secreto que ultrapassa palavras e frases", de que nos fala Clarice Lispector em um de seus melhores romances (LISPECTOR, 1977, p. 20); tampouco pode haver Literatura Infantil sem aquele "prazer espiritual" do qual nos fala Cecília Meireles (MEIRELES, 1979, p. 23), em livro dedicado ao assunto.

São exatamente os chamados aspectos estéticos, que enformam a Literatura Infantil, os responsáveis pela trama narrativa, pelo discurso ficcional, pela variedade de personagens e pelo arcabouço temporal que, no conjunto, tornam um texto essencialmente literário. Considerada até pouco tempo um gênero literário secundário, a literatura infanto-juvenil passou a ter uma importância incomensurável na atualidade, atuando ainda na construção da própria cidadania da criança, facilitando o diálogo e a formação de uma consciência crítica no leitor-mirim. Desse modo, tanto o educador quanto os pais têm oportunidade de trabalhar conflitos infantis a partir de histórias que estimulem o imaginário infantil, mas também que levem em conta aspectos diversos da sociedade contemporânea.

\section{Referências Bibliográficas}

AMARAL, M. L. Criança é criança: literatura infantil e seus problemas. Petrópolis, RJ: Vozes, 1971.

COELHO, B. Contar histórias: uma arte sem idade. São Paulo:Ática, 1999.

COELHO, N.N. A literatura infantil. São Paulo: Quíron, 1984.

CUNHA, M.A.A. Literatura Infantil - teoria e prática. São Paulo: Ática, 1999.

FURNARI, E. O amigo de Juliana. Disponível em: $<$ http://revistaescola.abril.com.br/lingua-portuguesa/pratica-pedagogica/amigo-juliana423378.shtml> Acesso em 20 jun. 2014.

LISPECTOR, C. A hora da estrela. Rio de Janeiro:Nova Fronteira, 1977.

MEIRELES, C. Problemas da literatura infantil. São Paulo: Summus, 1979.

NORONHA, D.M. Escola e literatura: o real e o possível. In: ZILBERMAN, R.(org). O ensino de literatura no segundo grau. Campinas, SP: Cadernos da ALB, s.d.

PALO, M.J.\& OLIVEIRA, M.R. Literatura Infantil - Voz de Criança. São Paulo: Ática, 1992.

RAPPAPORT, C.R. et Alii. Teorias do Desenvolvimento. Conceitos Fundamentais. São Paulo: EPU, 1981. 